\title{
Variability and its limits in bilingual word recognition
}

\author{
A morphological priming study
}

\author{
Harald Clahsen and Anna Jessen \\ University of Potsdam
}

\begin{abstract}
This study examines the processing of morphologically complex words focusing on how morphological (in addition to orthographic and semantic) factors affect bilingual word recognition. We report findings from a large experimental study with groups of bilingual (Turkish/German) speakers using the visual masked-priming technique. We found morphologically mediated effects on the response speed and the inter-individual variability within the bilingual participant group. We conclude that the grammar (qua morphological parsing) not only enhances speed of processing in bilingual language processing but also yields more uniform performance and thereby constrains variability within a group of otherwise heterogeneous individuals.
\end{abstract}

Keywords: German, inflection, morphology, L2 processing, masked priming

While most psycholinguistic research has focused on discovering general (potentially universal) mechanisms of language processing, there is also a rich body of experimental research on variability in linguistic performance across different languages and different individuals and on the limits of variability in language processing. One important line of this research examines how linguistic diversity shapes language processing. There are numerous reports in the experimental literature that the human language processor is affected by a particular language's linguistic properties; see Clahsen (2016) for a review. Another recent line of psycholinguistic research that focuses on variability investigates individual differences in language processing, for example with respect to morphological priming (Andrews \& Lo, 2013; Beyersmann, Casalis, Ziegler \& Grainger, 2015). Other studies employed event-related brain potentials (ERPs) and reported individual differences in the amplitudes of familiar language-related ERP components (viz. $\mathrm{N} 400, \mathrm{P} 600$ ), which were taken to indicate different degrees of sensitivity to 
lexical-semantic as opposed to grammatical violations across individuals (e.g. Tanner \& Van Hell, 2014; Kim, Oines, \& Miyake, 2018).

In bilingualism research, variability measures of language performance have been claimed to signify improvements in an individual's linguistic skill and proficiency (Segalowitz \& Segalowitz, 1993; Segalowitz, Segalowitz, \& Wood, 1998). The core finding is that increases in proficiency/skill not only yield faster speed of processing but, additionally, reduced levels of variability across individuals for a given task and condition. In lexical decision tasks, for example, increases in familiarity and practice with the target words were found to lead to shorter response times (RTs) and to less RT variability (Harrington, 2006; Solovyeva \& DeKeyser, 2018). Following Segalowitz and Segalowitz (1993), reduced RT variability is indicative of more automatic performance due to the elimination of controlled, less efficient components of processing. As a result, a given task may be accomplished by using fewer slow and temporally variable processes such as self-monitoring and error correction, yielding faster and more uniform performance across participants (Phillips, Segalowitz, O'Brien, \& Yamasaki, 2004). It should be noted, however, that while some studies provided support for the proposed practice-induced and proficiency-related changes in RT speed and RT variability (e.g. Akamatsu, 2008; Lim \& Godfroid, 2015; Solovyeva \& DeKeyser, 2018), other studies failed to replicate this pattern (e.g. Hulstijn, van Gelderen \& Schoonen, 2009; Rodgers, 2011).

The present study does not focus on learning or improvements in skill, but instead seeks to employ measures of RT speed and RT variability to investigate word recognition. Our focus is on how different kinds of linguistic cues, in particular morphological ones, modulate RT speed and RT variability of bilingual word recognition. We tested a heterogeneous group of 110 (Turkish-German) bilinguals in their second language ('L2'), i.e. in their German, in comparison to a group of 32 functionally monolingual ('Li') speakers of German using a visual masked-priming experiment. In priming experiments, a prime word is presented before the word on which participants perform a task, typically a lexical (word/non-word) decision. Morphological priming is defined as shorter RTs to target words when they are preceded by morphologically related than by unrelated prime words. Morphological priming is essentially a speed-up effect, due to facilitated lexical access. As Stanners, Neisser, Hernon and Hall (1979:403) who were the first to report morphological priming effects explained: “...the base verb and suffix are partitioned prior to memory access and the base verb is then directly accessed". According to this view, the underlying mechanism is morphological decomposition, by which a prime word form is segmented into its component parts which then directly facilitates and speeds up the recognition of the target word. Morphological priming effects have since been replicated in many 
studies and for a variety of languages; see Marslen-Wilson, 2007 and Amenta and Crepaldi, 2012 for reviews. What has been neglected, in this research, however, is that speed-up effects of lexical decision RTs may be accompanied by reduced RT variability.

\section{Previous research on morphological priming}

Experimental research on morphological processing seeks to uncover the linguistic cues and processes the recognition system relies on for morphologically complex words during language comprehension. A commonly used experimental technique to gain insight into these processes is morphological priming. As mentioned above, a robust finding from priming experiments is that RTs to target words are shorter when they are preceded by morphologically related prime words than by unrelated ones, e.g. talked $\rightarrow$ talk vs. laughed $\rightarrow$ talk. Although such priming effects have been interpreted in morphological terms (supposedly resulting from morphological decomposition of the prime word and subsequent stem repetition in the target, e.g. [talk]ed $\rightarrow$ [talk]), morphologically related prime-target pairs typically also exhibit more overlap in meaning and in orthographic/phonological form than corresponding unrelated prime-target pairs. The challenge for interpreting results from priming experiments is to determine whether any facilitation of target word recognition is genuinely morphological or due to, for example, orthographic or semantic prime-target overlap.

Different priming techniques are available. Primes and targets may be presented in the same modality or cross-modally, for example primes auditorily and targets visually. Primes may be presented long enough to allow for overt recognition or in a visual mask for a very short period of time which only allows for partial recognition. Targets may be presented immediately at the offset of the prime words or with a delay. Amongst these different techniques, masked visual priming with immediate lexical decision has been argued to most directly tap into morphological decomposition during word recognition; see Marslen-Wilson (2007) for a review. To take an example, Rastle, Davis, and New (2004) conducted a maskedpriming experiment in which prime words were only presented for $42 \mathrm{~ms}$ comparing (i) prime-target pairs such as brother $\rightarrow$ broth in which the prime word consists of a potential but non-existent bimorphemic form ([broth]-er), (ii) morphologically related prime-target pairs (e.g. teacher - teach), and (iii) prime-target pairs such as brothel $\rightarrow$ broth in which the prime word does not contain a potential derivational or inflectional affix. Rastle et al. (2004) obtained the same significant priming effects on target RTs for (i) and (ii), but not for (iii). This contrast cannot be explained in terms of semantic or surface-form relatedness between primes and 
targets. Instead, Rastle et al.s finding provides support for a decomposition mechanism that is sensitive to word-internal morphological structure and segments (potential) morphemes/affixes from their stems.

Previous masked-priming studies have consistently reported significant priming effects for regularly inflected prime words in groups of L1 speakers of typologically different languages, e.g. English (Kielar, Joanisse, \& Hare, 2008; Silva \& Clahsen, 2008) French (Meunier \& Marslen-Wilson, 2004) and Turkish (Kırkıc1 \& Clahsen, 2013). Furthermore, smaller masked-priming effects have been found for irregular inflection, for example in L1 English (e.g. Pastizzo \& Feldman, 2002; Rastle, Lavric, Elchlepp, \& Crepaldi, 2015) and L1 German (Neubauer \& Clahsen, 2009). Previous masked-priming studies testing bilingual speakers in their nonnative L2, on the other hand, have produced mixed results. For regular inflection, some studies reported L1-like morphological priming effects for the bilingual speakers' L2s (English: Feldman, Kostić, Basnight-Brown, Đurđević \& Pastizzo, 2010; Voga, Anastassiadis-Symeonidis \& Giraudo, 2014; French: Coughlin \& Tremblay, 2015; Spanish: Foote, 2017), whereas other studies found no or significantly reduced facilitation in the bilingual's L 2 - (relative to L1 control groups) from regularly inflected prime words (English: Silva \& Clahsen, 20o8; German: Jacob, Heyer, \& Veríssimo, 2018; Neubauer \& Clahsen, 2009; Turkish: Kırkıcı \& Clahsen, 2013). As regards priming from irregular inflection, there is (to our knowledge) only one masked-priming study on bilinguals, Neubauer and Clahsen (2009). This study reported reduced target RTs after irregularly inflected prime words (German $-n$ participles) in both L1 speakers of German and in the L2 German of Polish/German bilinguals, even though for the bilinguals, the $(-n)$ priming effect was only marginally significant.

Masked morphological priming effects have been attributed to morphological decomposition during reading. In recent research, three variants of this mechanism have been most prominently discussed. One proposal is the affix-stripping account (e.g. Rastle et al., 2004) according to which affixes are segmented from their stems during visual word recognition, yielding stem-repetition effects from concatenated morphologically complex prime words, e.g. for [walk]ed - walk. A second account posits a single-route full decomposition mechanism (e.g. Stockall \& Marantz, 2006) that exhaustively decomposes all morphologically complex words into their basic morphemes, irrespective of the presence of overt affixes. The third account, edge-aligned embedded word activation (e.g. Grainger \& Beyersmann, 2017), holds that the processor activates embedded words or stems at both edges of a given letter string, effectively segmenting a concatenated morphologically complex word's stem from its affixes (such as walk from walked). These three segmentation mechanisms have been proposed to account for results from masked-priming effects from regularly inflected prime words in L1 speakers. To 
explain masked-priming effects from irregularly inflected prime words, the existence of a second (weaker) source of priming at the lexical level has been proposed where irregularly inflected word forms (irrespective of whether or not they have overt affixes) share a lexical entry with their base form; see Crepaldi, Rastle, Coltheart and Nickels (2010), Bosch, Veríssimo and Clahsen (2019), Veríssimo (2018). Consequently, a prime word such as fell or kept indirectly facilitates the recognition of fall and keep, respectively (through shared lexical entries), rather than directly (through stem repetition) as for regularly inflected prime words such as walked - walk.

The question of how the bilingual language processor makes use of an inflected word's morphological cues for word recognition and lexical access has remained controversial. Some researchers have argued that morphological decomposition of inflected word forms functions less efficiently in a bilingual speaker's L2 testified by reduced or no facilitation under masked-priming conditions (e.g. Silva \& Clahsen, 2008; Kırkıcı \& Clahsen, 2013; Farhy, Veríssimo \& Clahsen, 2018). Other researchers suggested that the morphological decomposition mechanism is fully operational in L2 processing in the same way as in L1 speakers (e.g. Foote, 2017). Clearly, more research is needed on morphological processing in bilingual word recognition to resolve these controversies.

\section{The present study}

This study examines the role of linguistic cues on language processing. We specifically ask how morphological cues affect the speed and the variability of lexical decision response times in bilingual word recognition using a masked-priming experiment. The morphological phenomenon we examined is past participle formation in German, which (together with a present-tense auxiliary form) encodes past-time events. All past participle forms of German carry one of two endings, $-t$ or $-n$. Regular so-called 'weak' participle forms are suffixed with $-t$ and do not exhibit any stem changes (e.g., öffnen - geöffnet 'to open - opened'), whereas irregular so-called 'strong' forms have the ending $-n$ and sometimes but not always undergo (phonologically unpredictable) stem changes (e.g. gehen gegangen 'to go - gone, schlafen - geschlafen 'to sleep - slept'). In addition, past participles may contain the augment ge-, the distribution of which is prosodically determined by primary word stress, rather than by morphological structure. The augment is inserted if the stem is stressed on the first syllable (which is most commonly the case in German). If, however, primary word stress occurs on a different stem syllable, the participle form appears without ge-, e.g. übersétzen übersétzt 'to translate - translated[+participle]'. 
Following previous research (e.g. Neubauer \& Clahsen, 2009), we expect the baseline condition (viz., lexical decision on target words preceded by unrelated prime words) to yield slower RTs in bilingual/L2 word recognition than in monolingual/L1 controls. As regards morphological priming, we expect to replicate the significant speed-up effects on target RTs (e.g. Marslen-Wilson, 2007) that have been consistently obtained for regular inflection in previous L1 masked-priming experiments. For irregular participle forms, previous L1 research (e.g. Rastle et al., 2015) leads us to expect smaller priming effects than for regular ones. With respect to morphological priming effects in bilinguals, there is more uncertainty given the mixed findings from previous research. One possibility would be that our group of bilinguals exhibits the same morphological priming effects as our Li control group. Alternatively, morphological decomposition may function less efficiently in a bilingual's L2 yielding reduced or no morphological priming effects. As regards possible effects of transfer from the L2 speakers' L1, we are not expecting any substantial effects in this particular case, because Turkish is typologically different from German with Turkish exhibiting almost exclusively regular (agglutinating) morphology rather than the regular/irregular contrast found in inflectional systems of German and other Germanic languages. Furthermore, transfer effects in masked morphological priming experiments do not seem to be particularly consistent. Silva and Clahsen (2008), for example, showed that L2 speakers from typologically different languages (Chinese, Japanese, German) had parallel patterns of masked-priming results in their L2 (English), irrespective of the properties of their native language.

A novel component of the current study concerns the examination of morphological cues on RT variability in word recognition and lexical access. Previous research found lexical decision RTs in a bilingual speaker's L2 to be more variable than in L1 speakers (e.g. Harrington, 2006). We expect to replicate this contrast, by showing that the baseline condition (viz., lexical decision with prime words unrelated to the target words) produces more RT variability in our bilingual/L2 participant group than in the L1 control group. Concerning potential effects of morphology on RT variability, we hypothesize that morphological decomposition is an efficient, automatic, subconscious processing mechanism that is driven by a word's internal morphological structure. Increased processing efficiency has been argued to reduce RT variability, by eliminating controlled, slower components of processing; see Segalowitz and Segalowitz (1993) and subsequent research on 'automatization'. If these assumptions are correct, morphologically structured prime words should reduce RT variability relative to the unrelated baseline condition. This is because the decomposition mechanism be it through affix stripping, morpheme decomposition, or embedded word/stem activation - constrains (or even eliminates) less automatic, slower processes that 
participants may otherwise apply to the unrelated baseline condition. In this way, morphological decomposition may lead to reduced RT variability (relative to the baseline condition), i.e. to more homogeneous performance across participants. Furthermore, previous research indicates more consistent and larger effects for regular than for irregular inflectional prime words (Rastle et al., 2015). We expect to find a corresponding contrast for RT variability, with a more substantially reduced RT variability from regularly than from irregularly inflected prime words.

\section{Methods}

\section{Participants}

We recruited a group of 110 Turkish-German bilinguals (henceforth 'BIL', 53 women, 57 men) between the ages of 18 and 59 years (mean age: 32.95 years, SD: 10.7), all of whom had acquired Turkish as an L1 from birth and German as an additional language from different ages onwards. They were living in the Berlin/ Potsdam area for 2 years or longer at the time of testing. We refer to our participant group as 'bilingual' in a broad sense, to include both early and sequential bilinguals who use both of their two languages (Turkish and German) on a more or less daily basis. As a measure of the participants' skills in German, we used the 'European Language Certificates' (telc, 2015). The German version of the TELC test has a maximum score of 50 points and tests vocabulary and grammar in written cloze tasks. Five participants who scored below 30 were excluded prior to any data analysis. In addition, the data from two participants were lost due to technical problems. Another seven participants had low (lexical decision) accuracy scores in our main experiment ( $<50 \%$ for nonce words, and $<60 \%$ for words) and were therefore also removed from any further data analysis. Finally, one participant reported to have been able to see and read at least some of the prime words. As in this case the primes were apparently not masked, this participant was not included in the data analysis.

The remaining 95 participants ( 52 women, 43 men) of the BIL group had a mean TELC score of 43.17, (SD: 5.5, range 30-50) for German. Although this puts them at the $\mathrm{C}_{1}$ level according to the Common European Framework Reference for Languages (CEFR, Council of Europe, 2001), the BIL group's TELC score is considerably lower than that of the German L1 control group (means: 43.17 vs. 48.8); see below. The BIL group self-rated their skill of German (on a 10-point scale) as relatively high (mean: $8.55, \mathrm{SD}: 1.5$, range 5-10) and their daily language use of German (on a five-point scale) as quite common (Spoken German: mean: 3.97, SD: 0.96, range 1-5; written German: mean: 3.93, SD: 0.98, range 1-5). The 
95 participants of the BIL group varied considerably with respect to their level of education (30 individuals had degrees from university, 27 from high schools, 26 from vocational schools, and 12 participants from secondary schools) as well as with respect to the age at which they started to learn German (mean; 10.04 years, SD: 7.8, range o to 30) and consequently, their length of exposure to German (mean: 22.34 years, SD: 11.3, range 2-54 years).

The control group (henceforth 'CTR') consisted of 32 German native speakers (24 women; mean age: 27.34 years, SD: 6.73, range 18-50). All of them reported to have grown up with only German and at most weekly lessons in other languages (e.g., English) at school and sometimes preschool. Although at the time of testing almost all of them were able to speak and understand more than one language, we consider this group as functionally monolingual. All participants in the CTR group were either students at the local university or already had a university degree. They completed the TELC test and achieved a high mean score of 48.8 points (SD: 1.6, range $45-50$ ) out of a maximum of 50 points.

\section{Materials}

We tested $-t$ participles with unmarked stems and two types of $-n$ participles, (i) - $n$ participles with unmarked stems and (ii) $-n$ participles with marked (allomorphic) stems. These prime types were combined with target words that were first person singular present tense forms of the same verbs. There were $90 \mathrm{critical}$ prime-target pairs, 30 with - $t$ participle primes, e.g. gerettet - rette 'rescued rescue [1ps], and 60 with $-n$ participle primes, half of which without stem changes, e.g. gewaschen - wasche 'washed - wash [1ps]', and the other half with stem changes, e.g. geboten - biete 'offered - offer [1ps]'. A complete list of experimental items is shown in the appendix. For each critical prime-target pair, there was an unrelated baseline condition in which the target word was combined with a prime word that was not related in any way to the target (e.g. furchtbar - rette "horrible rescue [1ps]'). The unrelated primes were adjectives, adverbs and verbs. To ensure that the target words in the baseline condition were indeed semantically unrelated to their primes in this condition, we conducted a small scalar rating task using a 5-point Likert scale with 10 German native speakers (who did not take part in the masked-priming experiment). The materials consisted of the semantically related prime-target pairs (in this case meant as fillers to provide the possibility to use the full scale) as well the unrelated prime-target pairs of the regular morphological condition. The purpose of this rating task was to determine possible variability within unrelated control prime-target pairs with respect to semantic similarity. The results revealed a mean rating score of 1.15 (out of a maximum score of 5) 
for the unrelated prime-target pairs (with 1 meaning "absolutely not related"). The mean ratings for the 30 unrelated prime-target pairs were as follows: twelve items had a mean of 1, twelve of 1.1 or 1.2, three of 1.3, two of 1.5, and only one had a mean rating of 1.8 out of 5 . We conclude that there is very little variation amongst the unrelated control prime-target pairs in terms of semantic similarity. We selected all items, together with their (base 10 logarithmic-transformed) lemma and word-form frequency per million, from the dlexDB database (http:// www.dlexdb.de/query/kern/typposlem/). Both prime types (related and unrelated ones) were pairwise matched for length (in letters), as well as for lemma and word form frequency, on the basis of the log-transformed normalized frequency data of the dLEX corpus. All morphological primes as well as targets were also matched against each other as closely as possible for lemma and word form frequency; see Table 1. Following Sassenhagen and Alday's (2016) suggestion, the table reports information about matching for the selected variables in terms of descriptive rather than inferential statistics.

Two additional control conditions were included to test for the role of orthographic and semantic relatedness between primes and targets in our experiment. The orthographic control set contained 30 prime-target pairs with partial orthographic overlap (e.g., Flasche - Lasche - 'bottle' - 'strap') parallel to the one in the critical (morphological) conditions. We used the 'Match Calculator' (Davis, 2005; Davis \& Bowers, 2006), specifically the spatial coding measure, which revealed that the related prime-target pairs in the orthographic control condition (0.73, SD: 0.1 , range $0.44-0.88$ ) did not differ from the $-t$ participle and the $-n$ participles without stem change in terms of orthographic overlap (- $t$ participles: $0.73, \mathrm{SD}$ : 0.04 , range: $0.67-0.8 ;:-n$ participles without stem change: 0.72 , SD: 0.05 , range: $0.67-0.86)$. Unavoidably, however, $-n$ participles with stem changes exhibited less orthographic overlap with their targets than the orthographic control condition (- $n$ / with stem change: $0.66, S D$ : 0.06 , range: $0.5-0.8)$. The semantic control condition consisted of 30 prime-target pairs which were listed as synonyms/connotations (e.g. Doktor - Arzt 'doctor' - 'physician', Gebäude - Haus 'building' 'house') in two online synonym dictionaries of German (https: \www.synonyme .de; https: \|www.synonyme.woxikon.de). As unrelated primes we selected simplex nouns that were not related in any way to the target words, matched pairwise for length in letters, lemma and word form frequency to the related primes.

The prime-target pairs of the three morphological and the two control conditions were distributed over two counter-balanced experimental lists that were matched as closely as possible in terms of mean frequencies. Each list contained all 150 target words, but only one prime type (related or unrelated) for each target, so that each participant saw each target only once. To prevent participants from 
Table 1. Item properties of the morphological, orthographic and semantic conditions (means and standard deviations)

\begin{tabular}{|c|c|c|c|c|}
\hline & & \multicolumn{2}{|c|}{ Frequency per Mio (log-transformed) } & \multirow{2}{*}{$\begin{array}{l}\text { Length } \\
\text { (in letters) }\end{array}$} \\
\hline & & Lemma & Word form & \\
\hline \multirow[t]{6}{*}{$-t$ participles } & Target & $1.59(0.4)$ & $0.07(0.5)$ & $5.43(1.1)$ \\
\hline & & range: $1.0-2.38$ & range: $-1.01-1.0$ & range: $4-8$ \\
\hline & Prime & $1.59(0.4)$ & $0.87(0.5)$ & $8.43(1.1)$ \\
\hline & & range: $1.0-2.38$ & range: $-0.31-1.69$ & range: $7-11$ \\
\hline & Unrelated & $1.56(0.4)$ & $0.92(0.5)$ & $8.2(1.12)$ \\
\hline & & range: $0.67-2.46$ & range: $-0.11-1.75$ & range: $6-11$ \\
\hline \multirow[t]{6}{*}{ - $n$ participles (no stem change) } & Target & $1.91(0.8)$ & $0.4(0.8)$ & $5.0(0.83)$ \\
\hline & & range: $0.27-3.14$ & range: $-1.31-1.76$ & range: $4-8$ \\
\hline & Prime & $1.91(0.8)$ & $0.99(0.8)$ & $8.03(0.81)$ \\
\hline & & range: $0.27-3.14$ & range: $-1.79-2.22$ & range: $7-11$ \\
\hline & Unrelated & $1.77(0.8)$ & $1.18(\mathrm{o} .8)$ & $7.83(1.53)$ \\
\hline & & range: $-0.001-3.23$ & range: $-0.2-1.47$ & range: $5-11$ \\
\hline \multirow[t]{6}{*}{ - $n$ participles (with stem change) } & Target & $1.74(0.6)$ & $0.06(0.6)$ & $5.87(1.28)$ \\
\hline & & range: $0.68-2.84$ & range: $-1.33-1.37$ & range: $4-9$ \\
\hline & Prime & $1.74(0.6)$ & $0.88(0.6)$ & $8.8(1.21)$ \\
\hline & & range: $0.68-2.84$ & range: $-0.33-2.01$ & range: $7-11$ \\
\hline & Unrelated & $1.60(0.6)$ & $0.94(0.6)$ & $8.37(1.27)$ \\
\hline & & range: $0.42-2.82$ & range: $-0.2-2.1$ & range: $6-11$ \\
\hline \multirow[t]{6}{*}{ orthographic } & Target & $1.39(0.8)$ & $0.97(1.0)$ & $5.27(1.06)$ \\
\hline & & range: $-0.13-3.61$ & range: $-0.73-3.56$ & range: $4-7$ \\
\hline & Prime & $1.59(1.1)$ & $0.89(0.9)$ & $7.4(1.54)$ \\
\hline & & range: $-0.26-4.23$ & range: $-0.53-3.28$ & range: $5-11$ \\
\hline & Unrelated & $1.4(0.6)$ & $0.81(0.7)$ & $7.3(1.34)$ \\
\hline & & range: $0.36-3.03$ & range: $-1.01-1.8$ & range: $5-11$ \\
\hline \multirow[t]{6}{*}{ semantic } & Target & $1.52(0.5)$ & $1.26(0.5)$ & $5.33(1.56)$ \\
\hline & & range: $0.53-2.61$ & range: $-0.11-2.22$ & range: $4-10$ \\
\hline & Prime & $1.38(0.5)$ & $1.15(0.7)$ & $5.4(1.45)$ \\
\hline & & range: $0.35-2.3$ & range: $-1.13-2.11$ & range: $3-10$ \\
\hline & Unrelated & $1.44(0.6)$ & $1.18(0.7)$ & $4.33(1.65)$ \\
\hline & & range: $-0.16-2.76$ & range: $-0.54-2.23$ & range: $3^{-11}$ \\
\hline
\end{tabular}


developing any response strategies for the experimental items, a set of 210 unrelated filler prime-target pairs was included, with 180 non-word targets and 30 word targets (nouns, adjectives and verbs), resulting in a total of 360 items per list. Each list contained 180 non-words as targets (which required a 'no'-response in the lexical decision task) and 180 word targets (which required a 'yes' response). Non-words were created by changing one to three letters of existing German words. Overall, the ratio of items in which primes and targets were related to each other in any way (i.e., morphologically, semantically or orthographically) in each experimental list was $20.83 \%$.

\section{Procedure}

Participants were tested in a quiet lab room at the University of Potsdam or at the Technical University Berlin. Before the experiments started, participants filled in a demographic background questionnaire and signed a consent form. Half of the participants completed the TELC language test before the experiment, the other half afterwards. The CTR group also completed the TELC test and followed the same procedures as the BIL group participants. Participants received either credits or a fee for participation. Before the masked-priming experiment, participants received oral and written instructions informing them that they would see a number of existing and non-existing words and that they should decide as quickly as possible whether the word existed in German or not by pressing one of two buttons on a gamepad (Yes-responses were always elicited with the participants' dominant hand). If they had no further question, they could start the session with 8 practice trials, consisting of four words and four non-words as targets. After the practice session, participants were asked to identify the words they had seen during the practice session. None of the participants who were included in the data analysis reported that they had seen any of the primes.

Items were presented in the centre of the screen, and lexical decision times were measured by the DMDX software (Forster \& Forster, 2003). Each trial started with a $500 \mathrm{~ms}$ blank screen, followed by a forward mask (\#\#\#\#) consisting of a number of hashes equal to the letters of the following prime word. After the mask, the prime word was shown for 50ms. The prime was immediately followed by the corresponding target word, which stayed on screen until participants responded by a button press - or until $500 \mathrm{~ms}$ had passed. A time-out was set for responses longer than $5,000 \mathrm{~ms}$ in total (i.e., 4,500ms after the target disappeared). Two short breaks within the masked-priming experiment were offered (after 120 items), the length of which participants were free to decide. 


\section{Data analysis}

The experiment yielded accuracy scores and RTs on the participants' word/nonword button presses. Analysis of the RT data was carried out on correct responses only. Consequently, 5 of the 150 experimental targets were removed from any further analysis, since they elicited more than $40 \%$ incorrect 'no' responses in the BIL group ( 3 -t participle items: eignen 'to be suitable' widmen 'to dedicate', leugnen 'to deny', 1 - $n$ /no stem change item: hauen 'to beat', and 1 orthographic item: Lasche 'strap'). Furthermore, all time-outs and errors were also excluded prior to analysis of the RT data (BIL: $7.96 \%$, CTR: $6.9 \%$ ). Finally, in order to reduce the influence of outliers, we set cutoffs on the raw data to exclude extreme latencies (under $300 \mathrm{~ms}$ and over 2,00oms), which resulted in a further removal of $0.67 \%$ for the BIL and $0.02 \%$ for the CTR group.

In addition to mean RTs, we analysed the variability of RTs for each Group, Condition, and Prime Type. There are of course different ways of measuring variability of response times. Previous studies in bilingualism research have used a participant-based measure of variability of RTs (viz. the so-called 'coefficient of variance'), which is supposed to tap into an individual's linguistic skill and proficiency (Segalowitz \& Segalowitz, 1993). By contrast, for the present study we are specifically interested in how different kinds of linguistic cues, in particular morphological ones, modulate RT variability within the two participant groups. We therefore employed an item-level measure of variability, namely the mean absolute deviation ('MAD'), i.e., the average absolute deviation of each trial from the mean RT. The MAD scores were calculated on log-RTs (rather than on raw RTs) to neutralize any effects from different response speeds (e.g. in the two participant groups) on RT variability differences; see Wagenmakers and Brown (2007). To calculate the MAD scores, we first log-transformed the raw RTs, calculated the mean log-RT for each Condition, Prime type and Group, and then subtracted the log-RT of each trial from the corresponding mean RT. We then determined the absolute values of these deviations from the means, which were finally averaged to yield the MAD scores by Group, Condition, and Prime Type.

All statistical analyses were carried out with R (R Development Core Team), and the package lme4 (Bates, Meachler, Bolker, \& Walker, 2015). RTs and absolute deviations from the means were analysed with a series of linear mixed effects regression models with random effects for Participant and Item, and fixed effects for Prime Type (Related, Unrelated), Regularity $(-t,-n)$ or Condition (morphological, orthographic, semantic), and Group (CTR, BIL). For main effects and overall interactions, we employed sum-coded contrasts $(-0.5,0.5)$ to the factors Regularity, Prime Type and Group. Priming effects for a single condition were analysed with 
treatment contrasts and by releveling for each condition. As regards the random effects structure of the model, we initially constructed a maximal model that included random intercepts and slopes for Group and Prime Type by Item, and Prime Type and Condition by Participant, and their interactions (Barr, Levy, Scheepers, \& Tily, 2013). When this maximal model failed to converge, we iteratively simplified the random effects structure following Barr et al. (2013). Specifically, we removed only one random slope at a time, taken from the random slopes at the highest level for each random effect (e.g., the 2-way interaction between Prime Type by Condition for Participant, and then the 2-way interaction between Group and Prime Type for Item) and removing the term (by-participant or by-item) that explained the least variance. This procedure was repeated until the model converged. The fixed and random effects structure for the maximum model that converged for each analysis is reported in the Results section.

We first compared - $t$ vs. $-n$ participles, the latter taken as one group. We then compared $-n$ participles with and without stem change, by running the model on - $n$ participles only, with the factors Form (- $n$ with allomorphy, $-n$ without allomorphy) and Prime Type. If there were any differences between these two types of $-n$ participles, they were analysed separately, otherwise $-n$ participles were treated as one group.

We then included the two control conditions with the fixed factors Condition (morphological $(-t,-n)$, orthographic, semantic), Prime Type (related, unrelated) and Group (CTR, BIL), in order to test whether any significant effects found for the morphological conditions were also obtained for the control conditions.

\section{Results}

Table 2 presents accuracy scores, mean RTs (back-transformed), and mean absolute deviations (MADs, back-transformed) for the two participant groups, the three morphological conditions, and the two control conditions.

As regards accuracy, both groups achieved high scores of around 90\% or more correct responses across all conditions and prime types; see Table 2. We therefore did not perform any further analyses on the accuracy scores. 


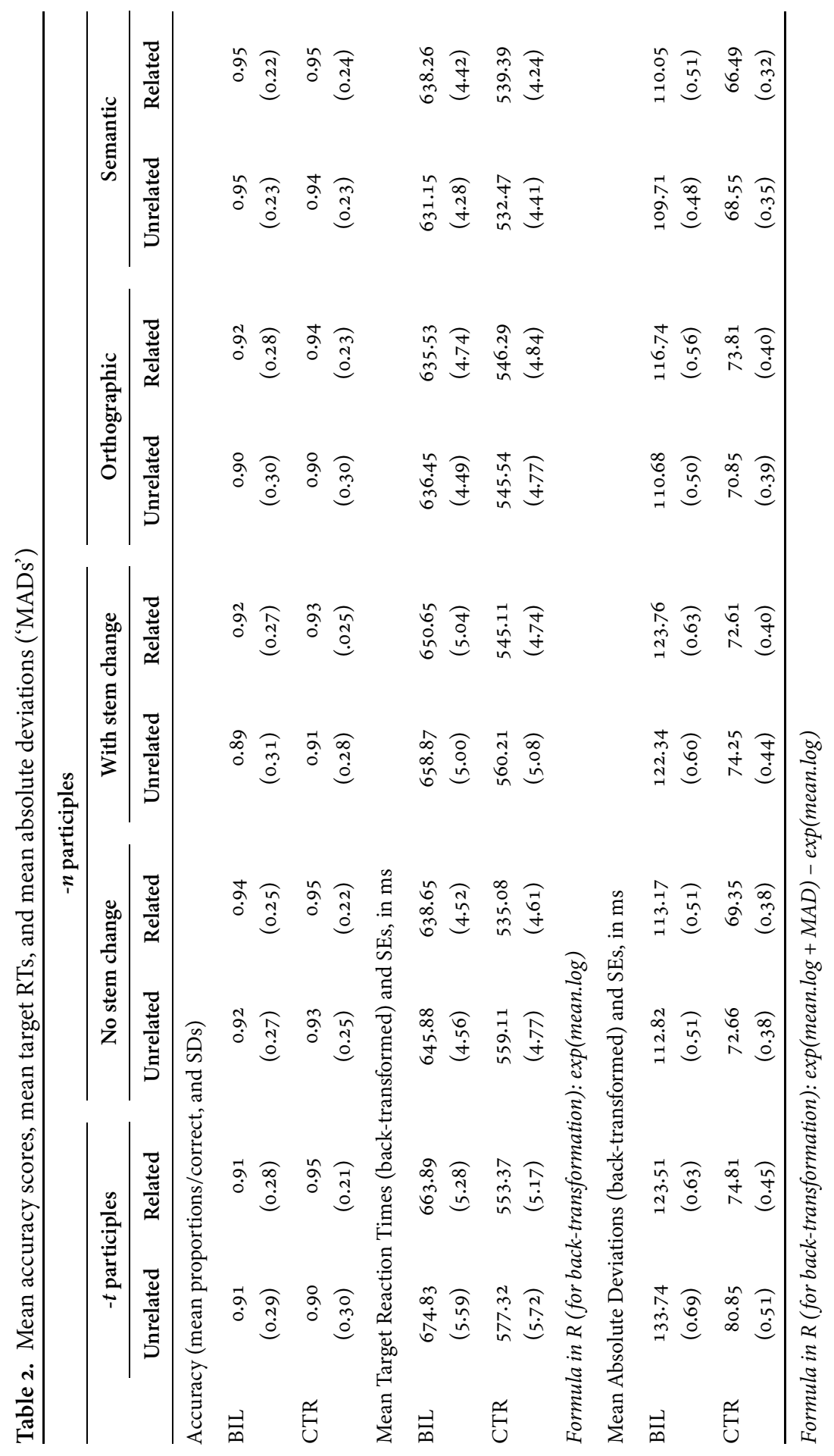




\section{Priming effects}

The differences between the mean target RTs for the related and the unrelated prime types shown in Table 2 represent the priming/inhibition magnitudes for the two participant groups in the morphological, orthographic, and semantic conditions. Table 3 a presents the best-fit overall model for the morphological conditions, $-t$ vs. $-n$ participles, and Table $3 b$ the corresponding models split by Group and Condition.

Table 3a reveals main effects for Prime Type, due to shorter RTs for related prime types compared to unrelated ones, and for Group, due to overall longer RTs for the BIL than the CTR group. Furthermore, a significant interaction of Prime Type and Group was found, due to larger priming effects for the CTR group. Additional analyses for the two morphological conditions and the two participant groups (Table $3 \mathrm{~b}$ ) revealed significant priming effects for $-t$ participles in both participant groups, whereas for $-n$ participles, only the CTR group showed reliable priming effects. Nevertheless, at least numerically, RTs were shorter after - $n$-participle primes than after unrelated controls in the BIL group as well; see Table 2. Note also that there were no reliable priming differences between the two subtypes of $-n$ participles, those with and those without stem changes, neither in the BIL nor the CTR group.

Table 3. Fixed effects from the models of the RTs for the morphological conditions

\begin{tabular}{lccc}
\hline Fixed effects & Estimate & Std. error & t \\
\hline (a) Overall Model & & & \\
(Intercept) & 6.4 & 0.01 & 372.1 \\
Main effect: Prime Type: (Rel. vs. Unrel.) & -0.03 & 0.005 & $-5.06^{\star}$ \\
Main effect: Group (CTR vs. BIL) & 0.17 & 0.03 & $5.83^{*}$ \\
Group (CTR vs. BIL) ${ }^{*}$ Prime Type (Rel. vs. Unrel.) & -0.02 & 0.01 & $-2.32^{\star}$ \\
Regularity (- $t$ vs. $-n){ }^{*}$ Prime Type (Related vs. Unrelated) & -0.009 & 0.01 & -0.85 \\
Group ${ }^{\star}$ Regularity (- $t$ vs. $\left.-n\right){ }^{\star}$ Prime T. (Rel.vs. Unrel.) & 0.002 & 0.02 & 0.12
\end{tabular}

Formula in $R$ (with sum-coded contrasts): $\log (R T) \sim$ Group ${ }^{*}$ Regularity ${ }^{*}$ Prime Type

$+(1+$ Regularity + Prime Type|Participant $)+(1+$ Prime Type $\mid$ Item $)$

(b) Models Split by Group

BIL Group

(Intercept)

$\begin{array}{clc}6.5 & 0.02 & 324.58 \\ -0.02 & 0.01 & -2.25^{*} \\ -0.01 & 0.007 & -1.65 \\ -0.01 & 0.01 & -0.96\end{array}$

Prime Type (Related vs. Unrelated, - $t$ participles)

Prime Type (Related vs. Unrelated, $-n$ participles)

Regularity $(t$ vs $n) *$ Prime Type (Related vs Unrelated

Formula in $R($ with treatment contrasts $): \log (R T) \sim$ Regularity ${ }^{*}$ Prime Type $+(1+$ Regularity + Prime
Type $\mid$ Participant $)+(1+$ Prime Type Item $)$ Type|Participant $)+(1+$ Prime Type|Item $)$ 
Table 3. (continued)

\begin{tabular}{lccc}
\hline Fixed effects & Estimate & Std. error & $\mathbf{t}$ \\
\hline BIL Group, $-n$ participles only & & & \\
(Intercept) & 6.5 & 0.02 & 308.44 \\
Prime Type (Related vs. Unrelated, no allomorphy) & -0.006 & 0.009 & -0.70 \\
Prime Type (Related vs. Unrelated, allomorphy) & -0.01 & 0.009 & -1.60 \\
Form (allo. vs. no allo) * Prime Type (Related vs. Unrelated) & -0.008 & 0.01 & -0.63 \\
Formula in R (with treatment contrasts): $\left(\log (R T) \sim\right.$ Form ${ }^{*}$ Prime Type $+(1+$ Form + Prime & \\
Type|Participant)+(1+Prime Type|Item) & & & \\
\hline
\end{tabular}

\section{CTR Group}

(Intercept)

$\begin{array}{clc}6.36 & 0.02 & 269.95 \\ -0.04 & 0.01 & -3.5^{*} \\ -0.04 & 0.008 & -4.3^{\star} \\ 0.006 & 0.01 & 0.45\end{array}$

Prime Type (Related vs. Unrelated, - $t$ participles)

Prime Type (Related vs. Unrelated, $-n$ participles)

Regularity $(t$ vs $n){ }^{\star}$ Prime Type (Related vs Unrelated)

Formula in $R$ (with treatment contrasts): $\log (R T) \sim$ Regularity ${ }^{*}$ Prime Type $+(1+$ Regularity + Prime Type|Participant $)+(1+$ Prime Type|Item $)$

\section{CTR Group, $-n$ participles only}

(Intercept)

Prime Type (Related vs. Unrelated, no allomorphy)

Prime Type (Related vs. Unrelated, allomorphy)

Form (allo. vs. no allo) ${ }^{\star}$ Prime Type (Related vs. Unrelated)

$\begin{array}{rll}6.33 & 0.02 & 268.91 \\ -0.04 & 0.01 & -3.61^{\star} \\ -0.03 & 0.01 & -2.36^{\star} \\ -0.01 & 0.02 & -0.92\end{array}$

Formula in $R$ (with treatment contrasts): $\left(\log (R T) \sim\right.$ Form ${ }^{\star}$ Prime Type $+(1+$ Form + Prime

Type|Participant $)+(1+$ Prime Type|Item $)$

Table 4. Fixed effects from the models of the RTs for the orthographic and semantic conditions, in comparison to the morphological conditions

Std.

Fixed effects

Estimate error $t$

(a) Overall model: Morphological vs. Orthographic Priming

\section{(Intercept)}

Prime Type: Orthographic (Related vs. Unrelated)

Group (CTR vs. BIL) * Prime Type/orthographic (Related vs.

Unrelated)

Condition (-t part. vs. Orth.) ${ }^{\star}$ Prime Type (Rel. vs. Unrel.)

Condition (- $n$ part. vs. Orth.) ${ }^{\star}$ Prime Type (Rel. vs. Unrel.)

Gr. (CTR vs.BIL) ${ }^{\star}$ Rel. T. (-t part. vs. Orth.) ${ }^{\star}$ Prime T. (Rel. vs. Unr.)

$\begin{array}{ccr}6.38 & 0.02 & 314.95 \\ 0.001 & 0.008 & 0.08 \\ -0.06 & 0.02 & -0.38\end{array}$

Gr. (CTR vs.BIL) ${ }^{\star}$ Rel. T. (- $n$ part. vs. Orth. $){ }^{\star}$ Prime T. (Rel. vs. Unr.)

$\begin{array}{lll}-0.3 & 0.01 & -2.59^{\star} \\ -0.02 & 0.01 & -2.2^{\star} \\ -0.01 & 0.02 & -0.68 \\ -0.02 & 0.02 & -0.91\end{array}$

Formula in $R$ (with sum-coded contrasts for the factor Group): $\log (R T) \sim$ Group ${ }^{*}$ Condition ${ }^{*}$ Prime Type + (1+Prime Type $\mid$ Participant $+(1+$ Prime Type Item $)$ 
Std.

Fixed effects

Estimate error $\quad \mathbf{t}$

(b) Overall model: Morphological vs. Semantic Priming

(Intercept)

$\begin{array}{ccc}6.36 & 0.02 & 304.63 \\ 0.01 & 0.008 & 1.52 \\ -0.001 & 0.01 & -0.05 \\ -0.04 & 0.01 & -3.62^{\star} \\ -0.04 & 0.01 & -3.42^{\star} \\ -0.02 & 0.02 & -0.95 \\ -0.02 & 0.02 & -1.23\end{array}$

Prime Type: Semantic (Related vs. Unrelated)

Group (CTR vs. BIL) * Prime Type - semantic (Related vs. Unrelated)

Condition (-t part. vs. Seman.) ${ }^{\star}$ Prime Type (Rel. vs. Unrel.)

Condition ( $n$ part. vs. Seman. ${ }^{\star}$ Prime Type (Rel. vs. Unrel.)

Gr. (CTR vs.BIL) * Rel. T. (-t part. vs. Seman.) ${ }^{\star}$ Prime T. (Rel. vs. Unr.)

Gr. (CTR vs.BIL) * Rel. T. ( $n$ part. vs. Seman.) ${ }^{\star}$ Prime T. (Rel. vs. Unr.)

$-0.02-0.02-1.23$

Formula in $R$ : same as for (a) above), releveled for semantic condition

(c) Models split up by Group

BIL Group: Morphological vs. Orthographic Priming

(Intercept)

$6.46 \quad 0.02 \quad 283.13$

Prime Type: Orthographic (Related vs. Unrelated)

$\begin{array}{lll}0.004 & 0.009 & 0.38\end{array}$

Condition (-t part. vs. Orth.) * Prime Type (Rel. vs. Unrel.)

$\begin{array}{lll}-0.03 & 0.01 & -1.95\end{array}$

Condition (- $n$ part. vs. Orth.) ${ }^{\star}$ Prime Type (Rel. vs. Unrel.)

$\begin{array}{lll}-0.01 & 0.01 \quad-1.29\end{array}$

Formula in R: $\log (R T) \sim$ Condition ${ }^{*}$ Prime Type $+(1+$ Prime Type + Condition $\mid$ Participant + $(1+$ Prime Type|Item)

BIL Group: Morphological vs. Semantic Priming

(Intercept)

$6.45 \quad 0.02 \quad 291.15$

Prime Type: Semantic (Related vs. Unrelated)

$0.01 \quad 0.008 \quad 1.48$

Condition (- $t$ part. vs. Seman.) ${ }^{\star}$ Prime Type (Rel. vs. Unrel.)

$\begin{array}{lll}-0.03 & 0.01 \quad-2.72^{*}\end{array}$

Condition ( $-n$ part. vs. Seman. $){ }^{\star}$ Prime Type (Rel. vs. Unrel.)

$\begin{array}{lll}-0.02 & 0.01 & -2.2^{*}\end{array}$

Formula in R: (as above)

CTR Group: Morphological vs. Orthographic Priming

(Intercept)

$6.3 \quad 0.02 \quad 302.65$

Prime Type: Orthographic (Related vs. Unrelated)

$\begin{array}{lll}0.001 & 0.01 & 0.075\end{array}$

Condition (-t part. vs. Orth.) ${ }^{\star}$ Prime Type (Rel. vs. Unrel.)

$\begin{array}{lll}-0.04 & 0.02 & -2.55^{*}\end{array}$

Condition ( $-n$ part. vs. Orth. $) \star$ Prime Type (Rel. vs. Unrel.)

$\begin{array}{lll}-0.03 & 0.02 & -2.52^{*}\end{array}$

Formula in $R$ : as above

CTR Group: Morphological vs. Semantic Priming

(Intercept)

$\begin{array}{lll}6.29 & 0.02 \quad 285.44\end{array}$

Prime Type: Semantic (Related vs. Unrelated)

$\begin{array}{lll}0.01 & 0.02 & 0.76\end{array}$

Condition (-t part. vs. Seman.) ${ }^{\star}$ Prime Type (Rel. vs. Unrel.)

$\begin{array}{lll}-0.06 & 0.02 & -2.64^{*}\end{array}$

Condition ( $n$ part. vs. Seman.) ${ }^{\star}$ Prime Type (Rel.vs. Unrel.)

$-0.05 \quad 0.02 \quad-2.68^{*}$

Formula in $R$ : as above 
Next, we performed parallel analyses for the orthographic and semantic primes and compared $-t$ and $-n$ participle priming to potential priming effects from the two control conditions, firstly over both participant groups (Tables $4 \mathrm{a}$ and $4 \mathrm{~b}$ ) and then separately for the two participant groups (Table 4c). The two overall models did not reveal any effects of Prime Type for the orthographic or the semantic condition, showing that pure orthographic or semantic relatedness does not yield reliable priming in the present experiment. Instead, these models yielded significant interactions of Prime Type and Condition (- $t /-n$ participles vs. orthographic/semantic) due to shorter RTs after morphologically related primes (relative to unrelated ones), but not after orthographically or semantically related primes. Analyses split by participant group (see Table 4c) again revealed no effects of orthographic or semantic priming and significant interactions of Prime Type and Condition. In the CRT group, these interactions were reliable for the two morphological conditions (- $t /-n$ participles) vs. the semantic and the orthographic conditions. For the BIL group, there was a significant interaction for the two morphological conditions vs. the semantic one. Likewise, for $-t$ participles vs. the orthographic condition there was an (almost significant) interaction of Prime Type and Condition in the BIL group $(t=1.95, p=.052)$, due to priming for $-t$ participles, but not for orthographic control primes. By contrast, there was no reliable interaction of Prime Type and Condition for the $-n$ participle and orthographic conditions in the BIL group, as none of them showed any reliable priming. Summarizing the results thus far, we found genuine morphological priming effects for $-t$ participles in both participant groups, albeit with a smaller magnitude in the BIL than the CTR group. Significant priming effects for - $n$ participles (both with and without stem change) were obtained in the CTR but not in the BIL group.

\section{Variability effects}

The differences between the mean absolute deviations (MADs) for the related and the unrelated prime types (shown in Table 2) represent the amount by which morphological, orthographic and semantic cues reduce or increase RT variability for the two participant groups. We performed the same analyses on the variability scores as for the priming effects. Tables 5 and 6 present the best-fit overall model for the absolute deviations.

The overall model for the morphological conditions shown in Table (5a) reveals a main effect of Group, due to considerably more variability for the BIL group than the CTR group. Table 2 shows that there is actually very little variability within the CTR group across all conditions. Further examination of the variability within the BIL group (Table $5 \mathrm{~b}$ ) reveals an effect of Prime Type for $-t$ 
Table 5. Fixed effects from the models of the variability scores ('MAD') for the morphological conditions

Std.

Fixed effects

Estimate error

t

(a) Overall Model

(Intercept)

Main effect: Prime Type: (Rel. vs. Unrel.)

$\begin{array}{clc}0.2 & 0.006 & 27.69 \\ -0.004 & 0.004 & -1.04 \\ -0.06 & 0.01 & -5.68^{\star} \\ 0.003 & 0.007 & 0.4 \\ -0.006 & 0.008 & -0.74 \\ -0.01 & 0.01 & -1.0\end{array}$

Main effect: Group (CTR vs. BIL)

Group (CTR vs. BIL) * Prime Type (Rel. vs. Unrel.)

Regularity (-t vs. $n){ }^{\star}$ Prime Type (Related vs. Unrelated)

Group $($ CTR vs. BIL $){ }^{\star}$ Condition $(-t$ vs. $-n) \star$ Prime T. (Rel.vs.

$-0.01$

0.01

$-1.0$

Unrel.)

Formula in $R: M A D \sim$ Group ${ }^{*}$ Regularity ${ }^{\star}$ Prime Type $+(1+$ Condition $\mid$ Participant $)+(1+$ Prime Type|Item)

(b) Models Split by Group

\section{BIL Group}

(Intercept)

$\begin{array}{cll}0.2 & 0.008 & 26.5 \\ -0.02 & 0.007 & -2.20^{*} \\ -0.03 & 0.03 & -1.03 \\ -0.02 & 0.008 & -2.45^{\star}\end{array}$

Prime Type (Related vs. Unrelated, $t$-participles)

ipant $)+(1+$ Prime Type $\mid$ Item $)$

Prime Type (Related vs. Unrelated, $n$-participles)

Regularity ( $-t$ vs. $-n){ }^{\star}$ Prime Type (Related vs. Unrelated)

$\begin{array}{ccc}0.21 & 0.009 & 23.64 \\ 0.004 & 0.006 & 0.57 \\ 0.005 & 0.006 & 0.95 \\ -0.002 & 0.009 & -0.23\end{array}$

BIL Group, $n$ participles only

(Intercept)

Prime Type (Related vs Unrelated, no allomorphy)

Prime Type (Related vs Unrelated, allomorphy)

Form (allo. vs. no allo) * Prime Type (Related vs. Unrelated)

$\begin{array}{ll}-0.002 & 0.009\end{array}$

Formula in R: MAD Condition * Prime Type $+(1+$ Prime Type|Participant $)+(1+$ Prime Type|Item $)$

\section{CTR Group}

(Intercept)

$\begin{array}{clc}0.14 & 0.08 & 17.22 \\ -0.005 & 0.008 & -0.65 \\ 0.0004 & 0.006 & 0.08 \\ -0.005 & 0.01 & -0.5\end{array}$

Prime Type (Related vs. Unrelated, $t$-participles)

Prime Type (Related vs. Unrelated, $n$-participles) $-0.005$

Regularity (-t vs. $-n){ }^{\star}$ Prime Type (Related vs. Unrelated)

Formula in R: : MAD $\sim$ Regularity * Prime Type $+(1+$ Regularity $\mid$ Participant $)+(1+$ Prime Type $\mid$ Item $)$

\section{CTR Group, $n$ participles only}

\section{(Intercept)}

Prime Type (Related vs Unrelated, no allomorphy

$\begin{array}{ccc}0.14 & 0.009 & 15.68 \\ -0.001 & 0.007 & -0.10 \\ -0.0001 & 0.007 & -0.02 \\ -0.001 & 0.01 & -0.06\end{array}$

Form (allo. vs. no allo) ${ }^{\star}$ Prime Type (Related vs. Unrelated)

Formula in R: :MAD Form * Prime Type $+(1+$ Form $\mid$ Participant $)+(1+$ Prime Type Item $)$ 
Table 6. Fixed effects from the models of the variability scores ('MAD') for the orthographic and semantic conditions, in comparison to the morphological conditions

Std.

Fixed effects

Estimate error

t

(a) Overall Models: Morphological vs. Orthographic Variability

(Intercept)

Prime Type: Orthographic (Related vs. Unrelated)

$\begin{array}{ccr}0.17 & 0.01 & 21.40 \\ 0.01 & 0.006 & 1.27 \\ -0.006 & 0.01 & -0.58\end{array}$

Group (CTR vs. BIL) * Prime Type/orthographic (Related vs.

Unrelated)

Condition (-t part. vs. Orth.) ${ }^{\star}$ Prime Type (Rel. vs. Unrel.)

Condition ( $n$ part. vs. Orth. $){ }^{\star}$ Prime Type (Rel. vs. Unrel.)

$\begin{array}{lll}-0.02 & 0.01 \quad-2.04^{\star}\end{array}$

Gr. $\left(\right.$ CTR vs. BIL) ${ }^{\star}$ Condition (-t part. vs. Orth.) ${ }^{\star}$ Prime T. (Rel. vs.

$\begin{array}{lll}-0.005 & 0.01 & -0.71\end{array}$

Unr.)

Gr. $($ CTR vs.BIL $){ }^{\star}$ Condition ( $n$ part. vs. Orth. $)$ * Prime T. (Rel. vs. $\begin{array}{lll}0.02 & 0.02 & 0.97\end{array}$ Unr.)

Formula in R:MAD $\sim$ Group ${ }^{*}$ Condition ${ }^{*}$ Prime Type $+(1+$ Condition $\mid$ Participant $)+(1+$ Prime

Type|Item)

Overall Models: Morphological vs. Semantic Variability

(Intercept)

$\begin{array}{ccc}0.17 & 0.01 & 21.05 \\ -0.004 & 0.01 & -0.76 \\ -0.004 & 0.01 & -0.38\end{array}$

Prime Type: Semantic (Related vs. Unrelated)

Group (CTR vs. BIL) * Prime Type - semantic (Related vs.

$$
-0.004
$$$$
\begin{array}{lll}
-0.006 & 0.01 \quad-0.66
\end{array}
$$

Condition (-t part. vs. Seman.) * Prime Type (Rel. vs. Unrel.)

$0.007 \quad 0.01 \quad 0.95$

Condition ( $n$ part. vs. Seman. $){ }^{\star}$ Prime Type (Rel. vs. Unrel.)

$\begin{array}{lll}0.01 & 0.02 \quad 0.87\end{array}$

Gr. $($ CTR vs.BIL $){ }^{\star}$ Cond. (-t part. vs. Seman.) ${ }^{\star}$ Prime T. (Rel. vs.

Unr.)

Gr. (CTR vs.BIL) * Cond. (- $n$ part. vs. Seman.) ${ }^{\star}$ Prime T. (Rel. vs. $\quad \begin{array}{llll}-0.0003 & 0.01 & -0.02\end{array}$ Unr.)

Formula in $R: M A D \sim$ Group ${ }^{*}$ Condition ${ }^{*}$ Prime Type $+(1+$ Condition $\mid$ Participant $)+(1+$ Prime Type|Item)

(b) Models Split by Group

BIL Group

(Intercept)

$\begin{array}{ccc}0.2 & 0.006 & 21.9 \\ 0.13 & 0.006 & 1.62 \\ -0.03 & 0.01 & -2.75^{*} \\ -0.01 & 0.01 & -0.73 \\ -0.01 & 0.01 & -1.44 \\ 0.01 & 0.01 & 0.94\end{array}$

Prime Type: Orthographic (Related vs. Unrelated)

Condition (-t part. vs. Orth.) ^ Prime Type (Rel. vs. Unrel.)

Condition (- $n$ part. vs. Orth.) ${ }^{\star}$ Prime Type (Rel. vs. Unrel.)

Condition (-t part. vs. Seman.) ${ }^{\star}$ Prime Type (Rel. vs. Unrel.)

Condition ( $n$ part. vs. Seman.) ${ }^{\star}$ Prime Type (Rel. vs. Unrel.) 
Table 6. (continued)

Std.

Fixed effects

Estimate error

$\mathbf{t}$

Formula in R: MAD Condition * Prime Type $+(1+$ Cond. $\mid$ Participant $)+(1+$ Prime Type $\mid$ Item $)$

CTR Group

(Intercept)

Prime Type: Orthographic (Related vs. Unrelated)

$\begin{array}{ccc}0.14 & 0.01 & 15.98 \\ 0.005 & 0.01 & 0.67 \\ -0.01 & 0.01 & -0.98 \\ -0.005 & 0.01 & -0.60 \\ 0.001 & 0.01 & 0.07 \\ 0.006 & 0.01 & 0.66\end{array}$

Condition (-t part. vs. Orth.) ${ }^{\star}$ Prime Type (Rel. vs. Unrel.)

Condition (- $n$ part. vs. Orth.) ${ }^{\star}$ Prime Type (Rel. vs. Unrel.)

Condition (-t part. vs. Seman.) * Prime Type (Rel. vs. Unrel.)

0.006

0.66

Formula in R: (as above)

participles and an interaction of Regularity and Prime Type. These results for the BIL group are due to considerably reduced MAD scores for related primes (relative to unrelated controls) in the - $t$ participle condition and no such contrast for the $-n$ participle condition (see Table 2). Moreover, there were no reliable differences in the variability scores between the two subtypes of $-n$ participles, those with and those without stem allomorphy. Only $-t$ participle primes lead to significantly reduced variability compared to the unrelated (baseline) condition within our BIL group. For the CTR group, by contrast, there were no reliable main effects or interactions.

Table 6 presents the best-fit models for the absolute deviations of the orthographic and semantic conditions in comparison to the morphological ones, firstly over both participant groups (Table 6a) and then separately for the two participant groups (Table $6 \mathrm{~b}$ ). The overall models show a significant interaction of Condition and Prime Type for the orthographic vs. the - $t$ participle condition, which - as the by-group models in Table $6 \mathrm{~b}$ show - is carried by the BIL group only, due to (significantly) reduced variability for related prime types in the $-t$ participle condition, and (numerically) larger MAD scores for related (than for unrelated) prime types in the orthographic condition. In the CTR group, on the other hand, neither morphological, nor orthographic, nor semantic relatedness had any effect on the variability scores.

Summarizing this section, the analysis shows that morphologically related (- $t$ participle) primes significantly reduced variability within the BIL group (albeit not in the CTR group). By contrast, $-n$ participles (as well as orthographic control and semantic control primes) did not have any reliable effects on the variability scores, neither in the BIL nor the CTR group. 


\section{Discussion}

The main experimental finding from the current study is that morphological relatedness significantly affected word recognition under masked-priming conditions in both participant groups, whereas orthographic and semantic relatedness did not have any reliable effects, for either the BIL or the CTR group. Morphology modulated both response speed and variability, albeit differently for the two participant groups. For the BIL group, regularly inflected $-t$ participle primes yielded significantly faster RTs and reduced RT variability, whereas in the CTR group, both $-t$ and $-n$ participle primes led to faster target RTs, but had no reliable effect on RT variability. In addition, we obtained longer RTs and more RT variability in the BIL group (relative to the CTR group) for all conditions and prime types.

\section{Effects of morphological relatedness on response speed and variability}

Our finding that morphologically-related prime-target pairs (unlike nonmorphologically related ones) yielded significant priming effects is consistent with the results of many (but not all) previous masked-priming studies. We found priming effects for morphologically related prime-targets pairs, but not for control prime-target pairs that exhibited the same degree of orthographic and semantic overlap as the critical morphological prime words with their targets. This indicates that the source of the masked-priming effects is indeed morphological in nature (e.g. Rastle et. al., 2004; Stockall \& Marantz, 2006), rather than due to orthographic and/or semantic prime-target overlap (e.g. Feldman, O'Connor, \& Moscoso del Prado Martin, 2009; Feldman, Milin, Cho, Moscoso del Prado Martin, \& O’Connor, 2015; Gonnerman, Seidenberg, \& Andersen, 2007).

The magnitudes of morphological priming were smaller in the BIL than in the CTR group, for both morphological prime types. Furthermore, the priming magnitudes were larger for regular $(-t)$ than for irregular $(-n)$ forms. Whilst the BIL group showed significant priming for regular but not for irregular forms, the CTR group exhibited significant priming effects for both regular and irregular forms, albeit with a numerically larger magnitude for the former than the latter. We can think of two possible interpretations for these differences.

The first possibility is that both morphological prime types engage the same morphological processing mechanisms and/or knowledge representations but that these mechanisms simply function less efficiently in the (BIL participants') L2 than in the (CTR participants') L1. This would be consistent with the finding that both regularly and irregularly inflected prime words yielded shorter target RTs relative to unrelated ones. Another possible interpretation for these results 
is that regular and irregular inflection engage different processing mechanisms, with regular forms producing more priming than irregular ones. This would be consistent with the finding that priming magnitudes were larger for regular than for irregular participle forms, again in both participant groups. On the basis of the priming results alone, it is hard to decide between these alternatives.

Concerning the results on variability, the current study is the first to present a detailed analysis of RT variability in (masked) morphological priming. Of particular interest are the results from the BIL group, for which we found a selective effect of morphological type, with significantly reduced target RT variability after regularly inflected prime words and no corresponding effect after irregular ones. Reduced RT variability in a given condition (relative to a control condition) has been attributed to gains in processing efficiency ('automatization') and the elimination of controlled slow processes (e.g. Segalowitz \& Segalowitz, 1993). If this assumption is correct, the RT variability results from the BIL group indicate a clear difference between regularly and irregularly inflected prime words, with more automatic processing for target words primed by regularly inflected forms, but not for those primed by irregular ones. In the CTR group, on the other hand, neither the two morphological prime types (- $t$ and $-n$ participles) nor the two control primes (orthographic, semantic) had any reliable effects on RT variability. This is likely to be a floor effect, due to relatively low RT variability in the (unrelated) baseline condition for the CTR group which were a magnitude smaller than those in the BIL group; see the MADs in Table 2. Possible modulations of RT variability by morphological (or other) prime types may therefore be harder to identify for the CTR group.

By combining the findings from the two measures (RT speed, RT variability), we can now better evaluate the two possible interpretations of the morphological priming results mentioned above. Suppose that regular and irregular inflection rely on the same processing mechanisms but that these mechanisms are simply less efficient in a bilingual speaker's L2 than in a native L1. If this was correct, we should have found that both morphological conditions produce the same (or at least a similar) effect on RT variability in the BIL group. This was clearly not the case, however. Whilst regular primes significantly reduced variability in the BIL group relative to the unrelated baseline, there were no corresponding effects or numerical trends for irregular primes (see Table 2). According to the second interpretation, regular and irregular inflection involve different mechanisms, which is more in line with our findings. Regularly inflected primes (unlike irregular ones) lead to significant increases in target response speed (compared to the unrelated baseline) in the BIL group and to significantly reduced target RT variability, i.e. more homogeneous performance amongst participants. 


\section{Mechanisms of morphological processing}

Current models of morphological processing have posited (different variants of ) a morpho-orthographic decomposition mechanism to account for facilitated target word recognition after morphologically related prime words under maskedpriming conditions: affix stripping (e.g. Rastle et al., 2004), single-route full decomposition (Stockall \& Marantz, 2006), and edge-aligned embedded word activation (Grainger \& Beyersmann, 2017). These models only provide a partial account of our findings. The results from the regular (-t participle) condition (which yielded significant priming effects) as well as the results from the semantic and the orthographic control conditions (which did not yield any reliable facilitation) in the two participant groups are consistent with these models, indicating genuine morphological decomposition as the source of facilitated target word recognition after $-t$ participle primes. The results from the irregular ( $-n$ participle) condition are, however, more difficult to explain for these accounts. From the perspective of 'affix-stripping', one would have expected parallel results for the two morphological prime types, as they both contain segmentable endings. This was clearly disconfirmed, particularly by the BIL group's data. The two other models lead us to expect more facilitation from $-n$ participles without stem changes (e.g. geschlafen $\rightarrow$ schlafe 'slept $\rightarrow$ sleep') than for those with stem changes (e.g. gesungen $\rightarrow$ singe 'sang $\rightarrow$ sing'). According to the single-route full decomposition model, this is because stem changes require additional processes (viz., phonological readjustments) that are not needed for inflected forms without stem changes. According to the embeddedword-activation account, a target word's base stem should be less activated from a prime word's embedded allomorphic stem than in cases in which the same stem is activated by the prime and the target word. Our results do not support these predictions. Instead, irregular (- $n$ participle) forms yielded parallel results irrespective of whether or not they contained stem changes.

Models that posit two distinct sources for masked morphological priming effects (e.g. Crepaldi et al., 2010; Bosch et al., 2019; Veríssimo, 2018) offer a more promising account for our findings. One source is the above-mentioned morphoorthographic segmentation mechanism, in one of its variants (viz., affix stripping, full decomposition, embedded stem/word activation). The second source is through morphological relatedness at the lexical level. Suppose that regular and irregular inflection differ from each other at this level in that irregular forms such as written in English or the corresponding German form (ge)schrieben constitute subentries within the lexical representation of corresponding base verbs, whereas verbs such as (to) open in English and the corresponding öffn(en) in German (for which there are no irregular forms) have base verb entries only, and no subentries (Clahsen, Sonnenstuhl, Hadler \& Eisenbeiss, 2001). On this account, facilitated target recognition from regular prime words arises directly, through morphological 
decomposition and subsequent stem repetition, and indirectly from irregular prime words, through the subentry activating the base stem at the lexical level. Hence, prime words such as written and geschrieben, for example, initially access their corresponding form-level access representations without any kind of morphoorthographic segmentation. Subsequently, the processor targets the lexical subentries ([written], (ge) [schrieben]), which co-activate the corresponding base entries ([write], [schreib-]), the activation of which then feeds back to the form-level representation of written and (ge)schrieben yielding facilitated (visual) recognition of the target words write and schreibe (relative to an unprimed control condition). The direct route can be assumed to yield larger masked-priming effects (qua stem repetition) than the indirect one. In this way, the distinction between direct and indirect morphological facilitation accounts for the finding that masked-priming effects for regular inflection are greater than those for irregular inflection.

For our CTR group, we found a small (numerical) difference in this direction, indicating that both routes are functioning (almost) equally efficiently. In the BIL group, on the other hand, we found significant priming for regular inflection and no reliable priming for irregular inflection. Likewise, regular inflection yielded significantly reduced RT variability scores in the BIL group, whereas irregular inflection had no reliable effect on these scores. These results suggest full functionality of the direct route, but not of the indirect one in the BIL group. Possible reasons for that could be that the irregular verbs' lexical (sub)entries, and/or their connections to the corresponding base entries, and/or their links to the form-level access codes are not strong enough to yield efficient processing. Weaker lexical representations and networks in bilingual speakers are likely to be due to the fact that they receive less input in their L2 than functionally monolingual speakers of the same language, the so-called 'weaker links' hypothesis (Michael \& Gollan, 2005; Gollan, Montoya, Cera, \& Sandoval, 2008, among many others), which may hold not only for simplex lexical items but also for the lexical representations of irregular word forms and their connections.

\section{Conclusion}

The current study investigated the role of morphology for word recognition and lexical access focusing on how morphological cues affect bilingual speakers' lexical decision RTs and RT variability. We found genuine morphological priming effects, i.e. faster target RTs after morphologically related primes than after unrelated prime words, and no corresponding difference for orthographically and semantically related control primes. Morphological priming was larger after regularly inflected prime words than after irregular ones. Furthermore, morphological priming magnitudes were larger for the CTR group than the BIL group. In 
addition, we estimated how morphological, orthographic and semantic primes affected the variability of RTs in the two participant groups. While the CTR group participants performed quite homogeneously across conditions, the BIL group exhibited more RT variability. Most interestingly, regular primes (but not irregular ones) yielded significantly reduced RT variability in the BIL group. We interpreted these findings from the perspective of morphological processing models that posit different mechanisms and knowledge representations for regular and irregular inflection, morpho-orthographic decomposition for the former and shared morpho-lexical entries for the latter. Our findings show that the decomposition mechanism is highly robust yielding not only reliable morphological priming effects (in both participant groups) but also reduced RT variability in the BIL group, i.e., more uniform performance amongst otherwise heterogeneous individuals.

\section{Funding}

This research was supported by the Deutsche Forschungsgemeinschaft (DFG), Project ID 317633480, Collaborative Research Centre SFB 1287, Project Bo4 (PIs: Harald Clahsen, Claudia Felser).

\section{Acknowledgements}

This article has been awarded an Open Materials badge. Study Materials and Data are publicly accessible via the Open Science Framework at https://osf.io/4du2k/. Learn more about the Open Practices badges from the Center for Open Science: https:/osf.io/tvyxz/wiki.

We are grateful to all PRIM team members, particularly Laura Ciaccio, Serkan Uygun and João Veríssimo, for comments on an earlier version of this manuscript.

\section{References}

Akamatsu, N. (2008). The effects of training on automatization of word recognition in English as a foreign language. Applied Psycholinguistics, 29(2), 175-193. https://doi.org/10.1017/S0142716408080089

Amenta, S., \& Crepaldi, D. (2012). Morphological processing as we know it: An analytical review of morphological effects in visual word identification. Frontiers in Psychology, 3 , 232. https://doi.org/10.3389/fpsyg.2012.00232

Andrews, S., \& Lo, S. (2013). Is morphological priming stronger for transparent than opaque words? It depends on individual differences in spelling and vocabulary. Journal of Memory and Language, 68(3), 279-296. https://doi.org/10.1016/j.jml.2012.12.001 
Barr, D. J., Levy, R., Scheepers, C., \& Tily, H. J. (2013). Random effects structure for confirmatory hypothesis testing: Keep it maximal. Journal of Memory and Language, 68(3), 255-278. https://doi.org/10.1016/j.jml.2012.11.001

Bates, D., Maechler, M., Bolker, B., \& Walker, S. (2015). Package 'lme4'. Available at: https:// cran.r-project.org/web/packages/lme4/index.html

Beyersmann, E., Casalis, S., Ziegler, J.C., \& Grainger, J. (2015). Language proficiency and morpho-orthographic segmentation. Psychonomic Bulletin \& Review, 22(4), 1054-1061. https://doi.org/10.3758/s13423-014-0752-9

Bosch, S., Veríssimo, J., \& Clahsen, H. (2019). Inflectional morphology in bilingual language processing: An age-of-acquisition study. Language Acquisition, 26(3), 339-36o. https://doi.org/10.1080/10489223.2019.1570204

Clahsen, H., Sonnenstuhl, I., Hadler, M. \& Eisenbeiss, S. (2001). The mental representation of inflected words: an experimental study of adjectives and verbs in German. Language, 77: 510-543. https://doi.org/10.1353/lan.2001.0140

Clahsen, H. (2016). Contributions of linguistic typology to psycholinguistics. Linguistic Typology 20: 599-614. https://doi.org/10.1515/lingty-2016-0031

Coughlin, C.E., \& Tremblay, A. (2015). Morphological decomposition in native and non-native French speakers. Bilingualism: Language and Cognition, 18(3), 524-542. https://doi.org/10.1017/S1366728914000200

Council of Europe. Council for Cultural Co-operation. Education Committee. Modern Languages Division. (2001). Common European Framework of Reference for Languages: learning, teaching, assessment. Cambridge University Press.

Crepaldi, D., Rastle, K., Coltheart, M., \& Nickels, L. (2010). 'Fell' primes 'fall', but does 'bell' prime 'ball'? Masked priming with irregularly-inflected primes. Journal of Memory and Language, 63(1), 83-99. https://doi.org/10.1016/j.jml.2010.03.002

Davis, C. J. (2005). N-Watch: A program for deriving neighborhood size and other psycholinguistic statistics. Behaviour Research Methods, 37, 65-70. https://doi.org/10.3758/BF03206399

Davis, C. J., \& Bowers, J.S. (2006). Contrasting five different theories of letter position coding: Evidence from orthographic similarity effects. Journal of Experimental Psychology: Human Perception and Performance, 32(3), 535-557.

Farhy, Y., Veríssimo, J., \& Clahsen, H. (2018). Do late bilinguals access pure morphology during word recognition? A masked-priming study on Hebrew as a second language. Bilingualism: Language and Cognition, 21(5), 945-951. https://doi.org/10.1017/S1366728918000032

Feldman, L. B., Milin, P., Cho, K.W., Moscoso del Prado Martín, F., \& O’Connor, P.A. (2015). Must analysis of meaning follow analysis of form? A time course analysis. Frontiers in Human Neuroscience, 9, 111. https://doi.org/10.3389/fnhum.2015.00111

Feldman, L. B., Kostić, A., Basnight-Brown, D. M., Đurđević, D. F., \& Pastizzo, M.J. (2010). Morphological facilitation for regular and irregular verb formations in native and nonnative speakers: Little evidence for two distinct mechanisms. Bilingualism: Language and Cognition, 13(2), 119-135. https://doi.org/10.1017/S1366728909990459

Feldman, L. B., O'Connor, P.A., \& del Prado Martín, F.M. (2009). Early morphological processing is morphosemantic and not simply morpho-orthographic: A violation of form-then-meaning accounts of word recognition. Psychonomic Bulletin \& Review, 16(4), 684-691. https://doi.org/10.3758/PBR.16.4.684 
Foote, R. (2017). The storage and processing of morphologically complex words in L2 Spanish. Studies in Second Language Acquisition, 39(4), 735-767.

https://doi.org/10.1017/S0272263115000376

Forster, K.I., \& Forster, J.C. (2003). DMDX: A Windows display program with millisecond accuracy. Behavior Research Methods, Instruments, \& Computers, 35(1), 116-124. https://doi.org/10.3758/BFo3195503

Gollan, T.H., Montoya, R.I., Cera, C., \& Sandoval, T.C. (2008). More use almost always means a smaller frequency effect: Aging, bilingualism, and the weaker links hypothesis. Journal of Memory and Language, 58(3), 787-814. https://doi.org/10.1016/j.jml.2007.07.001

Gonnerman, L. M., Seidenberg, M.S., \& Andersen, E.S. (2007). Graded semantic and phonological similarity effects in priming: Evidence for a distributed connectionist approach to morphology. Journal of Experimental Psychology: General, 136(2), 323-345. https://doi.org/10.1037/0096-3445.136.2.323

Grainger, J., \& Beyersmann, E. (2017). Edge-aligned embedded word activation initiates morpho-orthographic segmentation. Psychology of Learning and Motivation 67, 285-317. https://doi.org/10.1016/bs.plm.2017.03.009

Harrington, M. (2006). The lexical decision task as a measure of L2 lexical proficiency. EUROSLA Yearbook, 6(1), 147-168. https://doi.org/10.1075/eurosla.6.10har

Hulstijn, J.H., Van Gelderen, A., \& Schoonen, R. (2009). Automatization in second language acquisition: What does the coefficient of variation tell us? Applied Psycholinguistics, 30 (4), 555-582. https://doi.org/10.1017/S0142716409990014

Jacob, G., Heyer, V., \& Veríssimo, J. (2018). Aiming at the same target: A masked priming study directly comparing derivation and inflection in the second language. International Journal of Bilingualism, 22(6), 619-637. https://doi.org/10.1177/1367006916688333

Kielar, A., Joanisse, M.F., \& Hare, M.L. (2008). Priming English past tense verbs: Rules or statistics? Journal of Memory and Language, 58(2), 327-346. https://doi.org/10.1016/j.jml.2007.10.002

Kim, A.E., Oines, L., \& Miyake, A. (2018). Individual differences in verbal working memory underlie a tradeoff between semantic and structural processing difficulty during language comprehension: An ERP investigation. Journal of Experimental Psychology: Learning, Memory, and Cognition, 44(3), 406-420.

Kırkıc1, B., \& Clahsen, H. (2013). Inflection and derivation in native and non-native language processing: Masked priming experiments on Turkish. Bilingualism: Language and Cognition, 16(4), 776-791. https://doi.org/10.1017/S1366728912000648

Lim, H., \& Godfroid, A. (2015). Automatization in second language sentence processing: A partial, conceptual replication of Hulstijn, Van Gelderen, and Schoonen's 2009 study. Applied Psycholinguistics, 36(5), 1247-1282. https://doi.org/10.1017/S0142716414000137

Marslen-Wilson, W.D. (2007). Processes in language comprehension. In M. G. Gaskell, G.T.M. Altmann, G. Altmann, \& P. Bloom (Eds), Oxford Handbook of Psycholinguistics, (495-524). Oxford University Press.

Meunier, F., \& Marslen-Wilson, W. (2004). Regularity and irregularity in French verbal inflection. Language and Cognitive Processes, 19(4), 561-580. https://doi.org/10.1080/01690960344000279

Michael, E. B., \& Gollan, T.H. (2005). Being and becoming bilingual. In J. Kroll, \& A. de Groot (Eds), Handbook of Bilingualism: Psycholinguistic Approaches (389-407). Oxford University Press. 
Neubauer, K., \& Clahsen, H. (2009). Decomposition of inflected words in a second language: An experimental study of German participles. Studies in Second Language Acquisition, 31(3), 403-435. https://doi.org/10.1017/S0272263109090354

Pastizzo, M.J., \& Feldman, L. B. (2002). Discrepancies between orthographic and unrelated baselines in masked priming undermine a decompositional account of morphological facilitation. Journal of Experimental Psychology: Learning, Memory, and Cognition, 28(1), 244-249.

Phillips, N.A., Segalowitz, N., O’Brien, I., \& Yamasaki, N. (2004). Semantic priming in a first and second language: Evidence from reaction time variability and event-related brain potentials. Journal of Neurolinguistics, 17(2-3), 237-262. https://doi.org/10.1016/S0911-6044(03)00055-1

Rastle, K., Davis, M.H., \& New, B. (2004). The broth in my brother's brothel: Morphoorthographic segmentation in visual word recognition. Psychonomic Bulletin \& Review, 11(6), 1090-1098. https://doi.org/10.3758/BF03196742

Rastle, K., Lavric, A., Elchlepp, H., \& Crepaldi, D. (2015). Processing differences across regular and irregular inflections revealed through ERPs. Journal of Experimental Psychology: Human Perception and Performance, 41(3), 747-760.

Rodgers, D. M. (2011). The automatization of verbal morphology in instructed second language acquisition. IRAL-International Review of Applied Linguistics in Language Teaching, 49(4), 295-319. https://doi.org/10.1515/iral.2011.016

Sassenhagen, J., \& Alday, P.M. (2016). A common misapplication of statistical inference: Nuisance control with null-hypothesis significance tests. Brain and Language, 162, 42-45. https://doi.org/10.1016/j.bandl.2016.08.001

Segalowitz, N.S., \& Segalowitz, S. J. (1993). Skilled performance, practice, and the differentiation of speed-up from automatization effects: Evidence from second language word recognition. Applied Psycholinguistics, 14(3), 369-385. https://doi.org/10.1017/So142716400010845

Segalowitz, S. J., Segalowitz, N.S., \& Wood, A.G. (1998). Assessing the development of automaticity in second language word recognition. Applied Psycholinguistics, 19(1), 53-67. https://doi.org/10.1017/S0142716400010572

Silva, R., \& Clahsen, H. (2008). Morphologically complex words in L1 and L2 processing: Evidence from masked priming experiments in English. Bilingualism: Language and Cognition, 11(2), 245-26o. https://doi.org/10.1017/S1366728908003404

Solovyeva, K., \& DeKeyser, R. (2018). Response time variability signatures of novel word learning. Studies in Second Language Acquisition, 40(1), 225-239. https://doi.org/10.1017/S0272263117000043

Stanners, R.F., Neiser, J. J., Hernon, W.P., \& Hall, R. (1979). Memory representation for morphologically related words. Journal of Verbal Learning and Verbal Behavior, 18(4), 399-412. https://doi.org/10.1016/Soo22-5371(79)90219-6

Stockall, L., \& Marantz, A. (2006). A single route, full decomposition model of morphological complexity: MEG evidence. The Mental Lexicon, 1(1), 85-123. https://doi.org/10.1075/ml.1.1.07sto

Tanner, D., \& Van Hell, J.G. (2014). ERPs reveal individual differences in morphosyntactic processing. Neuropsychologia, 56, 289-301. https://doi.org/10.1016/j.neuropsychologia.2014.02.002

telc gGmbH (Hrsg.), Kompetenzcheck Deutsch Beruf A1/A2/B1/B2/C1. Frankfurt am Main, 1. Auflage 2015. 
Veríssimo, J. (2018). Taking it a level higher: The LEIA model of complex word recognition. Poster presented at 'Architectures and Mechanisms for Language Processing' (AMLaP), Berlin, Germany.

Voga, M., Anastassiadis-Symeonidis, A., \& Giraudo, H. (2014). Does morphology play a role in L2 processing?: Two masked priming experiments with Greek speakers of ESL. Lingvisticae Investigationes, 37(2), 338-352. https://doi.org/10.1075/li.37.2.10vog Wagenmakers, E. J., \& Brown, S. (2007). On the linear relation between the mean and the standard deviation of a response time distribution. Psychological Review, 114(3), 830-841. https://doi.org/10.1037/0033-295X.114.3.830

\section{Appendix. Materials}

\section{Condition: -t participles}

\begin{tabular}{|c|c|c|}
\hline Prime related (participle) & Prime unrelated & Target (1st person singular) \\
\hline geregnet (rained) & schmutzig (dirty) & regne (rain) \\
\hline gelandet (landed) & dramatisch (dramatic) & lande (land) \\
\hline gewendet (turned) & fraglich (debatable) & wende (turn) \\
\hline gerichtet (directed/adjusted) & praktisch (handy) & richte (direct/adjust) \\
\hline getrocknet (dried) & relevant (relevant) & trockne $(d r y)$ \\
\hline geendet (ended) & weiblich (female) & ende (end) \\
\hline gezeichnet (drawn) & wiederholt (repeated) & zeichne (draw) \\
\hline gerechnet (calculated) & schwach (weak) & rechne (calculate) \\
\hline geheiratet (married) & furchtbar (terrible) & heirate (marry) \\
\hline gedeutet (interpreted) & gelenkt (steered) & deute (interpret) \\
\hline geöffnet (opened) & gefährlich (dangerous) & öffne (open) \\
\hline geleugnet (denied) & getaucht (dove) & leugne (deny) \\
\hline gearbeitet (worked) & gespielt (played) & arbeite (play) \\
\hline gebetet (prayed) & vertagen (postpone) & bete (pray) \\
\hline gestartet (started) & geklebt (glued) & starte (start) \\
\hline geeignet (bene suited/proper for so/sth) & gerecht (fair) & eigne (to suitable for) \\
\hline geredet (talked) & wertvoll (precious) & rede (talk) \\
\hline gewidmet (dedicated) & erlaubt (permitted) & widme (dedicate) \\
\hline gebildet (educated) & wichtig (important) & bilde (educate) \\
\hline gerettet (rescued) & fruchtbar (fertil) & rette (rescue) \\
\hline gewartet (waited) & doppelt (double) & warte (wait) \\
\hline geflüchtet (fled) & glaubhaft (believable) & flüchte (flee) \\
\hline
\end{tabular}




\begin{tabular}{lll}
\hline Prime related (participle) & Prime unrelated & Target (1st person singular) \\
\hline gemeldet (announced) & verstanden (understood) & melde (announce) \\
geleitet (guided) & hübsch (pretty) & leite (guide) \\
getötet (killed) & gefällt (like) & töte (kill) \\
geschaltet (switched) & korrigiert (corrected) & schalte (switch) \\
geatmet (breathed) & arabisch (arabic) & atme (breathe) \\
gekostet (cost) & angenehm (pleasant) & koste (cost) \\
geantwortet (replied) & zufrieden (content) & antworte (reply) \\
geordnet (sorted) & anständig (decent) & ordne (sort) \\
\hline
\end{tabular}

Condition: - $n$ participles without stem allomorphy

\begin{tabular}{|c|c|c|}
\hline Prime related (participle) & Prime unrelated & Target (1st person singular) \\
\hline gehauen (beaten) & geherrscht (reigned) & haue (beat) \\
\hline gegeben (given) & gesagt (said) & gebe (give) \\
\hline gewachsen (grown) & interessant (interesting) & wachse (grow) \\
\hline gelesen (read) & falsch (wrong) & lese (read) \\
\hline getragen (carried) & langsam (slow) & trage (carry) \\
\hline geschlagen (hit) & besonders (special) & schlage (hit) \\
\hline gegraben $(d u g)$ & akademisch (academic) & grabe (dig) \\
\hline gebacken (baked) & chronisch (chronical/ly) & backe (bake) \\
\hline gerufen (shouted) & später (later) & rufe (shout) \\
\hline gelassen (let) & größer (bigger) & lasse (let) \\
\hline gekommen (came) & gemacht (made) & komme (come) \\
\hline gespalten (split) & begabt (gifted) & spalte (split) \\
\hline gefangen (caught) & bequem (comfortable) & fange (catch \\
\hline gefahren (drove) & nämlich (namely) & fahre (drive) \\
\hline gemessen (measured) & beständig (durable) & messe (measure) \\
\hline gesehen (seen) & machbar (doable) & sehe (see) \\
\hline gehalten (held) & allgemein (general) & halte (hold) \\
\hline getreten (kicked) & einfach (simple) & trete (kick) \\
\hline geladen (loaded) & ängstlich (fearful) & lade (load) \\
\hline geheißen (named) & geflogen (flown) & heiße (name) \\
\hline gegessen (eaten) & gekämpft (fought) & esse (eat) \\
\hline gefallen (fallen) & schwerer (more difficult) & falle (fall) \\
\hline
\end{tabular}




\begin{tabular}{lll}
\hline Prime related (participle) & Prime unrelated & Target (1st person singular) \\
\hline gefressen (devoured) & männlich (male) & fresse (devour) \\
geraten (guessed/advised) & schnell (quick/fast) & rate (guess/advise) \\
geschlafen (slept) & garantiert (guaranteed) & schlafe (sleep) \\
gemahlen (ground) & dämlich (daft) & mahle (grind) \\
gelaufen (ran) & gewaltig (massive) & laufe (run) \\
gestoßen (jabbed) & geschoben (pushed/slipped) & stoße (jab) \\
gebraten (fried) & verirrt (gotten lost) & brate (fry) \\
gewaschen (washed) & häßlich (ugly) & wasche (wash) \\
\hline
\end{tabular}

Condition: - $n$ participles with stem allomorphy

\begin{tabular}{|c|c|c|}
\hline Prime related (participle) & Prime unrelated & Target (1 st person singular) \\
\hline gesprungen (jumped) & geschüttelt (shaken) & springe (jump) \\
\hline gesungen (sung) & schwierig (difficult) & singe (sing) \\
\hline geschwungen (swung) & gezögert (hesitated) & schwinge (swing) \\
\hline gehoben (lifted) & modern (modern) & hebe (lift) \\
\hline getroffen (met) & ständig (constantly) & treffe (meet) \\
\hline gestorben (died) & bezeichnet (marked) & sterbe (die) \\
\hline geschrieben (written) & verloren (lost) & schreibe (write) \\
\hline geklungen (sounded) & gebremst (braked) & klinge (sound) \\
\hline gewichen (given way to..) & korrekt (correct) & weiche (give way to..) \\
\hline gebunden (bound) & zerstört (destroyed) & binde (bind) \\
\hline geworben (advertised) & geritten (ridden) & werbe (advertise) \\
\hline gefunden (found) & richtig (right) & finde (find) \\
\hline geschworen (vowed) & gemütlich (snug/homely) & schwöre (vow) \\
\hline gewunden (twisted) & krankhaft (morbid) & winde (twist) \\
\hline geboten (offered) & geglaubt (believed) & biete (offer) \\
\hline gesprochen (talked) & kleiner (smaller) & spreche (talk) \\
\hline geholfen (helped) & leichter (lighter/easier) & helfe (help) \\
\hline geschwunden (faded) & intelligent (intelligent) & schwinde (fade) \\
\hline gesunken (sunk) & herrlich (splendid) & sinke (sink) \\
\hline gezwungen (forced to) & teilweise (partially) & zwinge (force to) \\
\hline gebrochen (broken) & dankbar (grateful & breche (break) \\
\hline geworfen (thrown) & lebendig (alive) & werfe (throw) \\
\hline
\end{tabular}




\begin{tabular}{lll}
\hline Prime related (participle) & Prime unrelated & Target (1st person singular) \\
\hline geschwommen (swum) & gewöhnlich (ordinary/usually) & schwimme (swim) \\
gestrichen (painted) & wunderbar (wonderful) & streiche (paint) \\
gewiesen (shown) & getanzt (danced) & weise (show) \\
gestohlen (stolen) & langweilig (boring) & stehle (steal) \\
getrunken (drunk) & ungeheuer (monstrous) & trinke (drink) \\
gefochten (fenced) & trainiert (trained) & fechte (fence) \\
geliehen (borrowed) & klüger (smarter) & leihe (borrow) \\
gegolten (applied/counted for) & gebessert (improved) & gelte (apply/count for) \\
\hline
\end{tabular}

Condition: Orthographic controls

\begin{tabular}{|c|c|c|}
\hline Prime related & Prime unrelated & Target \\
\hline betreuen (taking care of) & wandern (to hike) & Reue (remorse) \\
\hline kleiner (smaller) & drehen (to spin) & Leine (lead) \\
\hline löschen (delete) & stinken (to stink) & schenke ((I) give) \\
\hline schwindeln (to swindle) & schnarchen (to snore) & Windel (diaper) \\
\hline brüllen (to bellow) & dreckig (dirty) & Hülle (casing) \\
\hline berichten (to report) & suchen (to search) & Richter (judge) \\
\hline Schenkel (limb) & schwarz (black) & Enkel (grandson) \\
\hline getrennt (separated) & Apfel (apple) & rennt (runs) \\
\hline Abende (evenings) & Deckel (lid) & Ende (end) \\
\hline schweigen (to be silent) & streichen (to paint) & weigere (refuse) \\
\hline Firmen (companies) & kindlich (childlike) & Schirme (umbrellas) \\
\hline wachsam (alert) & Schmerz (pain) & Achse (axis) \\
\hline gedacht (thought) & Blätter (leaves) & Dach (roof) \\
\hline Flaschen (bottles) & Herbst (autumn) & Lasche (strip) \\
\hline hatten (had) & Knopf (button) & Ratte (rat) \\
\hline werden (to become) & brummen (to buzz) & Erde (earth/dirt) \\
\hline gewesen (bene) & Schrift (script) & Wesen (creatures) \\
\hline Farmen (farms) & Kleider (clothes) & Arme (arms) \\
\hline getaucht (dove) & gerutscht (slipped) & auch (too/as well) \\
\hline Schweine (pigs) & Schmutz (dirt) & weine (cry) \\
\hline Pinsel (paint brush) & trösten (to solace) & Insel (island) \\
\hline brauchen (to need) & treiben (to drift) & rauche ((I) smoke) \\
\hline
\end{tabular}




\begin{tabular}{lll}
\hline Prime related & Prime unrelated & Target \\
\hline Schmaus (feast) & geplatzt (to burst) & Maus (mouse) \\
schaust ((you) look) & lächeln (to smile) & Haus (house) \\
Klagen (complaints) & gegangen (gone) & Lage (position) \\
verwechseln (to confuse) & entscheiden (to decide) & Echse (lizard) \\
Fische (fishes) & Kreide (crayon) & Tisch (table) \\
angefacht (fanned) & Schmuck (jewelry) & Fach (compartment) \\
Lampe (lamp) & Schrank (closet) & Ampel (traffic light) \\
beschlossen (decided) & Gedächtnis (memory) & Schloss (castle/lock) \\
\hline
\end{tabular}

Condition: Semantic controls

\begin{tabular}{|c|c|c|}
\hline Prime related & Prime unrelated & Target \\
\hline Truhe (chest) & Tau $(d e w)$ & Kiste (box) \\
\hline Streit (fight/argument) & März (March) & Kampf (fight/battle) \\
\hline Zimmer (room) & Straße (street) & Raum (room/space) \\
\hline Rudel (pack) & Farbe (color) & Herde (herd) \\
\hline Schlips (neck tie) & Passage (passage) & Krawatte (neck tie/cravat) \\
\hline Doktor (doctor) & Presse (press) & Arzt (doctor med) \\
\hline Gardine (curtain) & Gazelle (gazelle) & Vorhang (curtain) \\
\hline Zentrum (center) & August (August) & Mitte (center/middle) \\
\hline Nummer (number) & Fenster (window) & Zahl (number/digit) \\
\hline Wind (wind) & Gold (gold) & Sturm (storm) \\
\hline Summe (sum) & Grenze (border) & Betrag (sum/amount) \\
\hline Foto (photo) & Land (country) & Bild (picture) \\
\hline Fass (barrel) & Wiese (meadow) & Tonne (barrel/ton) \\
\hline Seemann (seaman) & Tablette (pill) & Matrose (sailor) \\
\hline Orient (orient) & Gipfel (top/summit) & Osten (east) \\
\hline Hut (hat) & Lob (praise) & Mütze (cap) \\
\hline Gebäude (building) & Mantel (coat) & Haus (house) \\
\hline Becher (cup) & Name (name) & Tasse (cup) \\
\hline Geschäft (business) & Licht (light) & Betrieb (firm) \\
\hline Mauer (brick wall) & Nonne (nun) & Wand (wall) \\
\hline Ozean (ocean) & Kunde (customer) & Meer (sea) \\
\hline Dreck (dirt) & Treppe (stairs) & Schmutz (dirt/filth) \\
\hline
\end{tabular}




\begin{tabular}{lll}
\hline Prime related & Prime unrelated & Target \\
\hline Gedächtnis (memory) & Unternehmen (company/business) & Erinnerung (memory/reminder) \\
Beutel (pouch) & Forelle (trout) & Tasche (bag) \\
Boot (boat) & Burg (castle) & Schiff (ship) \\
Herd (stove) & Kuss (kiss) & Ofen (oven) \\
Bahn (train) & Hof (court) & Zug (train) \\
Rind (beef) & Roman (novel) & Kuh (cow) \\
Strom (river) & Tafel (blackboard/table) & Fluss (river/stream) \\
Fest (celebration) & Ufer (shore) & Feier (party) \\
\hline
\end{tabular}

\section{Address for correspondence}

Harald Clahsen

Potsdam Research Institute for Multilingualism

University of Potsdam

14476 Potsdam

Germany

harald.clahsen@uni-potsdam.de

D https://orcid.org/oooo-0oo2-6190-1318

\section{Co-author information}

Anna Jessen

Potsdam Research Institute for Multilingualism

University of Potsdam

ajessen@uni-potsdam.de

(iD) https://orcid.org/oooo-0oo2-2488-2533 